\title{
De las huelgas a los cortes de ruta: la historiografía sobre la protesta social en Argentina*
}

Mirta Zaida Lobato

Universidad de Buenos Aires

Este artículo examina la historiografía de las protestas sociales en Argentina a lo largo del siglo XX bajo el impulso de las protestas recientes que han provocado la renuncia de, al menos, tres presidentes. Los desafíos colectivos tienen formas y características distintas a lo largo del proceso histórico que los estudiosos han examinado desde diversas perspectivas teóricas y metodológicas. En el trabajo se detectan los temas relevantes, períodos y geografía de la protesta social así como los debates que se han suscitado alrededor de algunos conflictos como la semana trágica de 1919, el 17 de octubre de 1945 y el cordobazo, y las fuentes utilizadas.

PALABRAS ClAVE: Historiografía, Argentina, protesta social, movimientos sociales.

This article examines the historiography of social protest in Argentina during the twentieth century, inspired by the recent protests which prompted the resignation of at least three presidents. Collective protests have assumed different forms and characteristics throughout history, which scholars have examined from varying theoretical and methodological perpectives. The work identifies the relevant themes, periods and geography of social protest, as well as the debates aroused by such conflicts as the semana trágica of 1919, that of 17 October 1946, and the cordobazo. It also addresses the sources used to study these conflicts.

KEYwORDS: Historiography, Argentina, social protest, social movements.

El 19 y 20 de diciembre de 2001 se produjo en la ciudad de Buenos Aires una intensa movilización popular que provocó la renuncia del presidente Fernando de la Rúa. Los saqueos a supermercados y las manifestaciones callejeras golpeando cacerolas se sumaron a los innumerables cortes de ruta que desde 1994 se realizaron en diferentes zonas del país. La magnitud de la protesta popular impulsó la reflexión de historiadores, sociólogos, filósofos y analistas políticos sobre la naturaleza, las formas y

* Una versión preliminar fue presentada en la Mesa redonda "A Historiografía dos movimientos sociais na America Latina”, organizado en el marco del XXI Simposio Nacional de Historia, A historia no novo milenio: entre o individual e o coletivo, Universidade Federal Fluminense, Neiterói, RJ, 22 a 27 de julio 2001 y en el Proyecto UBACYT: Trabajadores cultura y política en Argentina 18901945 , donde he recibido sugerencias y comentarios. 
las características de los conflictos sociales que se produjeron en la Argentina, no sólo en la última década sino a lo largo del siglo XX.

Desde la conformación de la primera organización de trabajadores las diferentes formas de protesta y la organización gremial fueron un elemento central del conflicto social en la Argentina. Las huelgas ocurridas desde fines del siglo XIX estuvieron en el centro de las reflexiones sobre el papel del movimiento obrero en la historia argentina. Esas reflexiones se orientaron desde la década del setenta del siglo $X X$ hacia los denominados movimientos sociales, al conjunto de acciones colectivas (movimiento por los derechos humanos, movimiento de mujeres, movimiento juvenil, movimiento barrial o vecinal) que excedían las demandas específicas de los trabajadores.

En este artículo me propongo examinar la historiografía sobre el tema, en particular la que se produjo en los últimos años, al calor de la normalización institucional de la vida universitaria. Pero es imposible realizar un análisis de este tipo sin considerar la extensa bibliografía sobre los trabajadores, actores principales de las protestas a lo largo del siglo XX.'

Protestas y organizaciones obreras formaron parte de numerosas investigaciones e interpretaciones cuyo interés estaba en el desenvolvimiento político global o en el desarrollo económico del país. Esos estudios abordaron tres momentos claves de la historia argentina: el de la consolidación de una economía capitalista bajo la impronta de la producción agropecuaria para la exportación, el del peronismo con su particular vinculación con los trabajadores y el de los infructuosos intentos realizados para desperonizar a los sectores populares a partir del golpe de 1955. El comportamiento de los trabajadores permitía explicar la naturaleza de las "anomalías" argentinas como las características generales de las confrontaciones de clase.

De manera coincidente los estudios históricos señalan al período 1860-1930 como uno de gran expansión económica y de profundas transformaciones sociales. Resaltan también la importancia que adquirió el movimiento obrero desde fines del siglo $X I X$, y el predominio de socialistas y anarquistas en gremios y federaciones obreras, mayoritariamente

1 Par un examen de esta literatura puede consultarse Lobato, Mirta Zaida y Suriano Juan: "Historia del trabajo y de los trabajadores en la Argentina. Aproximaciones a su historiografía", en Marta Panaia (compiladora) Trabajo y empleo. Un abordaje interdisciplinario, EUDEBA-PAITE, Buenos Aires, 1996 y "Trabajadores y movimiento obrero: entre la crisis de los paradigmas y la profesionalización del historiador”, en Entrepasados, revista de historia n. ${ }^{\text {4/5, } 1993 .}$ 
urbanas, en un país cuyas bases económicas se sustentaban en la producción agropecuaria. De las características del funcionamiento económico y de los vínculos que establecían los actores involucrados así como del papel del Estado nacional se deriva - a mi juicio- un sólido núcleo interpretativo de la naturaleza del conflicto social y de las formas de la acción colectiva en la Argentina.

Así, autores como Gino Germani, Jorge Sabato y Ernesto Laclau han dibujado tres importantes interpretaciones que investigaciones posteriores han discutido o defendido. Germani ha enfatizado la importancia del proceso de modernización que provocaba una ruptura del patrón tradicional de comportamiento lo que favoreció tanto la conformación de organizaciones obreras como la participación en huelgas. Esta transformación se relacionaba estrechamente con el fenómeno de la inmigración que había modificado los estratos populares. Peones rurales, trabajadores sin oficios, artesanos y personal de servicio doméstico se convirtieron en obreros urbanos ocupados en la industria, el comercio, el transporte y los servicios. Esos nuevos trabajadores se movilizaron en las áreas "centrales" del país dando forma a un importante movimiento proletario cuya organización se logró a pesar de las dificultades y de la falta de reconocimiento de las "capas superiores" de la población. ${ }^{2}$

La consecuencia de este proceso fue para Germani la dificultad para incorporar progresivamente a los sectores populares a la vida de la Nación, lo que derivó en una escasa significación de los símbolos de la democracia para las "capas recién movilizadas". La lectura germaniana de "las disfunciones" de la sociedad integra el conflicto social y político, pues para él, el problema argentino residía en el peso de la población extranjera (trabajadores no incorporados políticamente por medio del sufragio universal masculino) y las dificultades para integrarlos dentro de la estructura democrática del país vía la conformación de partidos políticos. Esta situación adquirió una nueva dimensión en la década del treinta cuando se produjo la exclusión, por medios compulsivos, de las grandes "masas trasplantadas" del interior del país y transformadas súbitamente en obreros industriales. Estos trabajadores adquirieron significación política sin que se produjera la conformación de canales institucionales para que pudieran integrarse a la democracia; quedaban así en disponibilidad abriendo el camino para un

2 Germani, Gino: Política y sociedad en una época de transición. De la sociedad tradicional a la sociedad de masas, Paidós, Buenos Aires, 1968, págs. 168-230. 
movimiento "fascista y totalitario" como el peronismo. La interpretación de Germani ha estado en el centro de los debates sobre la constitución del movimiento peronista, sobre la relaciones entre Estado y trabajadores y sobre el papel de los sindicatos.

Para otros autores como Jorge Sabato ${ }^{3}$ o Ernesto Laclau ${ }^{4}$ la clave estaba en la economía - se refieren al período de auge de la economía agroexportadora (1860-1930)—y, en el peso de las coyunturas como factor desencadenante de los conflictos. Aunque es cierto que el interés de los autores es otro y que algunas de sus ideas pueden ser objeto de un debate particular, lo que me interesa destacar es como miran las consecuencias de la expansión económica para los actores. Jorge Sabato considera que la implantación múltiple de la clase dominante argentina en la agricultura, ganadería, comercio, finanzas e industria desplazó los conflictos y los contendientes. La clase dominante no tenía un antagonista social principal y los clivajes básicos del conflicto económico en el país quedaban dislocados respecto de los movimientos básicos del conflicto social, en vez de sumarse unos a otros. Aunque la clase dominante estaba enfrentada con el resto de la sociedad argentina rara vez ese enfrentamiento fue total, casi siempre se planteó de manera indirecta y habitualmente se dio en forma sucesiva con distintos grupos económicos y sociales.

Por otra parte, para este autor, los conflictos en el agro se expresaban fuera del sector, pues las necesidades de exportar estaban en contradicción con el abastecimiento de alimentos baratos. Al estimular la producción mejorando los precios agropecuarios, los alimentos se encarecían y, si los salarios no aumentaban, se deterioraba el nivel de vida de amplios sectores urbanos. Además, el funcionamiento de la economía desencadenaba toda una serie de contradicciones económicas y sociales que no se acumulaban ni forzaban alguna solución definitiva, ya sea en términos de desarrollo capitalista o de una revolución que cambie la estructuras sociales vigentes. En realidad, los conflictos parciales se desplazaban de un actor a otro, a veces se resolvían y otras se volvían a plantear de manera sucesiva. De modo que las tensiones y distensiones afectaban alternativamente a un sector u otro y creaba un círculo vicioso en el que las condiciones externas de

3 Sabato, Jorge F.: La clase dominante en la Argentina moderna. Formación y características, Grupo editor latinoamericano, Buenos Aires, 1998, págs. 154-162.

4 Laclau, Ernesto: "Modos de producción, sistemas económicos y población excedente. Aproximación histórica a los casos argentino y chileno", en Giménez Zapiola, Marcos (compilador): El régimen oligárquico. Materiales para su estudio, Amorrortu., Buenos Aires, 1975, págs. 20-40. 
la economía contribuían para amplificar o atenuar las controversias. La Argentina - dice Sabato - "terminaría por asemejarse a un trompo que gira vertiginosamente alrededor de problemas que se repiten una y otra vez, mientras en conjunto se desplaza lentamente — quizás hacia adelante, a menudo hacia atrás- y se desgasta cada vez más". 5

Ernesto Laclau mira en cambio la estructuración del modo de producción capitalista y la inserción de Argentina (el texto incluye el caso chileno) en el mercado mundial prestando atención a la conformación y características del mercado de trabajo. Para él, la integración de Argentina a la economía mundial vía la "renta diferencial" acentuaba la tendencia a la plena ocupación y producía elevados ingresos per cápita, lo que beneficiaba a la "oligarquía terrateniente" pero también a las clases medias y al "proletariado artesanal y de servicios". Según este autor, la situación tuvo una consecuencia clara en la dinámica de los conflictos: las clases medias, la clase obrera y los capitalistas industriales podían aumentar sus ingresos sólo en la medida en que se mantuviera el mecanismo expansivo de la economía, por eso sus reivindicaciones tendían a una redistribución de la renta en lugar de poner en tela de juicio la orientación agropecuaria del país. Los conflictos sociales surgidos en el interior del sistema tendían a reformarlo pero no a cuestionarlo.

Para Jorge Sabato como para Ernesto Laclau, los conflictos entre estratos de la burguesía y entre ella y las clases subalternas eran más coyunturales que estructurales y las líneas de ruptura social y por consiguiente política no habrían sido fijas sino variables. La clase dominante o la oligarquía terrateniente tuvieron la posibilidad de poner de su lado a grupos diversos de la sociedad, por ejemplo los sectores de clase media. Por eso para Sabato rara vez la clase dominante estuvo obligada a enfrentarse por sí sola a las clases dominadas. El movimiento obrero, concentrado en las ciudades, y particularmente en la ciudad de Buenos Aires, quedó aislado en sus demandas por transformaciones sociales de fondo y no pudo anudar alianzas sólidas y estables con otros grupos sociales.

Ni Sabato, ni Laclau, ni Germani tenían como preocupación central explicar la naturaleza, las características o las modalidades de los movimientos de protesta pero al preguntarse por el comportamiento de la clase dominante, por las características del mercado de trabajo y por la profundidad de las transformaciones sociales posaron sus miradas sobre los sec-

5 Sabato: La clase dominante ..., pág. 156 y 157. 
tores populares y encontraron que éstos, en mas de una oportunidad, sólo querían reformar el sistema sin cuestionarlo. De modo que dejaron abierto un interrogante sobre cuál era el significado que se atribuía a la generalización de las ideas de reforma o sobre cuál hubiera sido el rumbo de la sociedad argentina si las clases subalternas hubieran cuestionado el modelo económico. Y más aún, si en verdad las clases subalternas no habrían cuestionado el desarrollo capitalista o propugnado una "revolución" que cambie las estructuras políticas y sociales vigentes.

Frente a estas interpretaciones, la segunda mitad del siglo XX está fuertemente asociada al fenómeno del peronismo y, en un amplio arco de investigaciones, las referencias se centran en la inestabilidad política que devino con los intentos de desperonizar a los trabajadores, y en el poder de las organizaciones sindicales que actuaron como expresión del partido político proscripto.

A su vez, los estudios más específicos sobre el mundo del trabajo formularon nuevos interrogantes cuyas respuestas a veces alimentaban las hipótesis mencionadas y otras las debatían o impugnaban. Además, la extensa literatura socio histórica amplió su mirada sobre las causas, los protagonistas y los motivos de las acciones colectivas desde que se produjo la protesta popular en Córdoba en mayo de 1969 y a partir de los conflictos que ocurrieron durante la última dictadura militar.

Este artículo examina entonces una vasta producción historiográfica y para ello se divide el trabajo en tres secciones. La primera se refiere a los temas y a la geografía de la protesta social; en la segunda se analiza brevemente el tipo de fuentes utilizadas; y en la tercera se consideran los debates que se dieron.

\section{Temas, períodos y geografía de la protesta}

A comienzos del siglo $X X$ las clases trabajadoras se habían constituido como una clase social que diseñaba sus medios y formas de acción para mejorar las condiciones de vida y de trabajo; los actos obreros preocupaban a las autoridades nacionales y diferentes agentes planteaban la necesidad de prevenir y curar los males sociales.

Huelgas, boicots y manifestaciones fueron las tres formas de protestas más utilizadas por los trabajadores para hacer visibles sus reclamos. Pero las huelgas, sobre todo las generales, y las manifestaciones dieron el 
tono distintivo a la protesta social. En la Argentina se produjeron numerosas huelgas parciales y generales. ${ }^{6}$ Entre 1880 y 1900 no se produjeron huelgas generales aunque sí numerosos paros parciales cuyo número se incrementó en la actividad portuaria, en el transporte y en las manufacturas. Entre los años 1887 y 1907, 1904 fue el año donde se registró la mayor cantidad de huelgas y entre 1901 y 1910 se realizaron nueve huelgas generales impulsadas por los anarquistas, algunas de las cuales contaron con el apoyo de los socialistas. Las huelgas generales fueron masivas en 1902, 1907, 1909 y fragmentadas en 1905, 1908 y 1919.

En la década del veinte las huelgas generales solidarias fueron mayoritariamente parciales: en 1921 se realizó una huelga general en protesta por el asesinato de obreros por la nacionalista Liga Patriótica, en 1924 en repudio al asesinato de Kurt Wilkens en la cárcel y en 1927 se realizaron cuatro huelgas en solidaridad con Sacco y Vanzetti. La única huelga general masiva del período fue la que se realizó entre el 3 y el 8 de mayo en oposición al establecimiento de una ley de jubilaciones que se basara en el descuento de un porcentaje del salario obrero.

Las huelgas servían para presionar a los empresarios (por la jornada de 8 horas, por mayores salarios, por mejoras en las condiciones de trabajo y por el control de los espacios laborales) y fueron una fuente importante para alimentar la solidaridad de clase, sobre todo cuando se paraba en solidaridad con otros trabajadores o en defensa de los trabajadores reprimidos por la policía. La huelga fue definiéndose como el medio de lucha privilegiado a lo largo de todo el siglo XX y se convirtió en la herramienta fundamental empleada por los trabajadores organizados. Persiste en la actualidad en las huelgas convocadas por las organizaciones gremiales y muchas veces van acompañadas de ruidosas manifestaciones. Sin embargo han perdido el poder de una confrontación que en el pasado se basaba en el respeto y acatamiento de las bases obreras a dirigentes y organizaciones gremiales. La crisis del sindicalismo y la extensión de la desocupación y el empleo precario convirtieron a esta herramienta de lucha en un modo de acción obrera debilitado.

El desarrollo de las huelgas ha sido el tema central tratado en la bibliografía y el que ha generado algunos debates. Los boicots en cambio

6 Lobato, Mirta Zaida y Suriano Juan: “Argentina 1880-1930: Huelgas generales en un país agro-exportador", Latin American Labor News, Issue 2 \& 3, USA, y Korzeniewics, Roberto P.: "Labor unrest in Argentina, 1887-1907”, en Latin American Research Review, N. . 3, USA, 1989. 
no han recibido aún la atención de las investigaciones aunque aparecen mencionados en los Boletines del Departamento Nacional del Trabajo, en la prensa gremial y en algunas historias obreras militantes. ${ }^{7}$ Según un análisis de las resoluciones de los congresos obreros de principios de siglo, el boycott y el sabotaje fueron recursos aceptados como medios de acción directa. ${ }^{8}$ En la declaración de 1902 de la FORA (Federación Obrera Regional Argentina) se reconocía que el boicot y el sabotaje eran eficaces para la causa obrera y en 1903 la UGT (Unión Gremial de Trabajadores) admitía su utilidad aunque señalaban que no debía declararse sin la aprobación de la dirección. En 1905 la FORA volvió sobre el tema de la necesidad de consultar antes de usar "un arma eficaz y poderosa". Salvo estas menciones, la literatura específica no analiza ni el modo ni las condiciones en que se aplicó el boicot.

El sabotaje en cambio fue la herramienta que se asoció directamente a la resistencia peronista, luego del golpe de 1955 que desalojó a Perón del poder. Daniel James ha analizado la resistencia en las fábricas calificándola como "fundamentalmente espontánea, instintiva, confusa y acéfala" al menos en su fase inicial. ${ }^{9}$ La resistencia que ofrecieron las bases fue un punto importante de la negociación y el compromiso entre el gobierno y los líderes sindicales durante el gobierno de Lonardi, pero la ofensiva antiperonista llegó a las fábricas cuando el general Pedro Eugenio Aramburu se hizo cargo del poder. A partir de allí los dispositivos de la resistencia se ampliaron. No sólo fueron las huelgas y las protestas, se utilizaron repertorios de confrontación amplios: se "rompían" o "copaban" actos de otras fuerzas políticas, se hostilizaban a los oradores que apoyaban al gobierno, se realizaban sabotajes y atentados..$^{10}$ Los sabotajes en las fábricas y en los medios de transportes fueron moneda corriente y hasta se menciona la conformación de una "cultura del caño", en clara referencia a la práctica de colocar bombas (lanza panfletos, para levantar las vías del ferrocarril) que realizaban algunos militantes peronistas.

7 República Argentina, Boletín del Departamento Nacional del Trabajo, N. ${ }^{\circ} 44$, Buenos Aires, enero de 1920 .

8 Solomonoff, Jorge: Ideologías del movimiento obrero y conflicto social, Editorial Proyección, Buenos Aires, 1971.

9 James, Daniel: Resistencia e integración. El peronismo y la clase trabajadora argentina, 1946-1976, Sudamericana, Buenos Aires, 1990, pág. 79.

10 Melón, Julio César: "La resistencia peronista, alcances y significados", en Anuario IEHS, 8, Universidad Nacional del Centro, Tandil, 1993. 
Frente al desarrollo de las protestas en las áreas urbanas, los análisis sobre la conflictividad social en el campo son todavía escasos. ${ }^{11}$ Argentina es, en este sentido, un país de paradojas y entre las muchas existentes está la importancia de los aspectos sociales y culturales del mundo urbano en un país apoyado en el mundo rural. La modernización de la Argentina implicó una reestructuración social con la conformación de nuevas clases subalternas y hegemónicas. En la región pampeana tres fueron los actores sociales subalternos: peones-braceros, chacareros y colonos.

La debilidad de las manifestaciones conflictivas en el mundo rural parece darle la razón a Jorge Sabato y Ernesto Laclau, aunque trabajos recientes han mostrado la existencia de algunos conflictos suscitados entre trabajadores del transporte y del comercio vinculados a la agricultura, sobre todo en la década del veinte. ${ }^{12} \mathrm{~A}$ su vez, y aunque el foco ilumina a las protestas urbanas, Ofelia Pianeto ha establecido la importancia de la ocupación rural para las posibilidades de desarrollo de las protestas urbanas y explorado la coyuntura histórica de 1917-1921 en el ciclo de conflictividad social que se produjo en la ciudad de Córdoba. ${ }^{13}$

El análisis de la conflictividad del mundo rural se ha concentrado en la región pampeana donde colonos en armas, chacareros y peones en huelga se movilizaban a veces por sus demandas. La historiografía regional mostró sus límites para detectar, analizar y comprender lo que sucedía en algunas áreas rurales de las regiones extrapampeanas. Sin embargo, quisiera rescatar una investigación sobre la provincia de Santiago del Estero que muestra la diversidad de conflictos que podía suscitarse en la producción agrícola. La agricultura de Santiago del Estero se basaba en el riego, y el agua es el elemento en el que convergen las confrontaciones de los actores y la acción del estado provincial. El acceso al agua refleja las desigualdades existentes tanto en la distribución de los recursos como el poder e influencia de los regantes, por eso los agricultores confrontaron con los funcionarios de riego y con las autoridades de la provincia, denunciando el favoritismo con los grandes propietarios y los partidarios del gobierno. El

11 Ansaldi, Waldo: "Hipótesis sobre los conflictos agrarios pampeanos", en Ruralia, 2, Buenos Aires, junio, 1991 y Ansaldi, Waldo et. al: Conflictos obrero-rurales pampeanos (1900-1937), 3 volúmenes, Buenos Aires, CEAL, 1993.

12 En particular los trabajos de Eduardo Sartelli publicado en Ansaldi et al: Conflictos obreros rurales pampeanos ..., Vol. 1 y 3 .

13 Pianetto, Ofelia: "Mercado de trabajo y acción sindical en Argentina, 1890-1922", en Desarrollo Económico, vol. 24, N. ${ }^{\circ}$ 94, Buenos Aires, 1984 y "Coyuntura histórica y movimiento obrero. Córdoba, 1917-21”, en Estudios Sociales, N. ${ }^{\circ}$ 1, Santa Fé, 1991. 
agua fue el motivo de la movilización de los agricultores de localidad de La Banda durante los años de 1924, 1925 y $1926 .{ }^{14}$

Además, el análisis de las protestas y las estadísticas de los conflictos muestran el predominio de aquellas actividades que estaban concentradas en la región litoral, en particular en la ciudad de Buenos Aires. Esta visión homogeneizante existente en los estudios sobre trabajadores ha sido señalada en diferentes trabajos ${ }^{15}$ pero parece oportuno volver sobre lo mismo desde una posición distinta. A partir del proceso abierto en 1983 y de la reconstrucción de un entramado académico en las universidades nacionales se pasó efectivamente de una visión centralizada en la Nación y en Buenos Aires a una fragmentación que enfatizaba las particularidades de cada una de las regiones del país. Los investigadores que impulsaron ese proceso de renovación historiográfica, comienzan a mostrar signos de insatisfacción al evaluar que se reproducen y multiplican los mismos temas y problemas en escala reducida. Por ejemplo, las investigaciones sobre la formación del mercado de trabajo en Buenos Aires se multiplicaron para las provincias de Tucumán o Jujuy y las huelgas de trabajadores en algunas actividades económicas provinciales ocuparon la escena. ${ }^{16}$

Desde el punto de vista del mercado laboral, las investigaciones sobre la provincia de Buenos Aires marcaron el rumbo respecto a la interpretación sobre los mecanismos de constitución de la oferta de trabajadores, los rasgos de la demanda y la existencia de trabajadores que llevaban décadas resistiendo a integrarse al trabajo asalariado, lo que permitió prestar atención a las dificultades asociadas al trabajo intermitente.

14 Tasso, Alberto: "La protesta del agua. Una movilización de agricultores santiagueños en 1926", en Sociohistórica, Cuadernos del CISH, 7, Centro de investigaciones socio históricas, Facultad de Humanidades y Ciencias de la Educación, Universidad Nacional de La Plata, 2000. También lo fue durante la sequía de 1937 y 1938. En Loreto la población asaltó en reiteradas oportunidades los trenes que pasaban por la estación.

15 Lobato y Suriano: "Historia del trabajo y de los trabajadores ... y Mases, Enrique: La historia de los trabajadores y la perspectiva regional. Aportes para el debate, ponencia presentada en las XVII Jornadas de Historia Económica, Tucumán 20,21 y 22 de septiembre de 2000.

16 Sabato, Hilda y Romero L.A.: Los trabajadores de Buenos Aires: la experiencia del mercado, 1850-1880, Sudamericana, Buenos Aires, 1992; Blanc Bloquel, A. Et. al.: (1986-87), "Conformación del mercado de trabajo en la provincia de Santa Fe", en Anuario 12, Escuela de Historia, UNR, Rosario, 1986/87; Pianetto, Ofelia: "Mercado de trabajo y acción sindical en Argentina, 1890-1922”, en Desarrollo Económico, vol. 24, N. 94, Buenos Aires, 1984; Campi, Daniel: "Captación y retención de la mano de obra por endeudamiento. El caso de Tucumán en la segunda

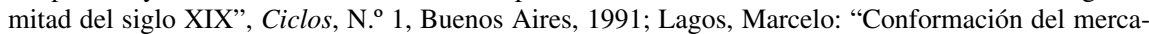
do laboral en la etapa de despegue de los ingenios azucareros jujeños (1880-1920)", en Campi Daniel (comp.): Estudios sobre la industria azucarera II, Universidad Nacional de Tucumán, Tucumán, 1992. 
Además, la noción de coacción fue la clave para explicar los mecanismos mediante los cuales buscaron encauzar y modelar los comportamientos y las costumbres de los sectores populares en las provincias litorales y del noroeste. A fuerza de describir la represión de la "vagancia" y de los "malos entretenimientos" fue cobrando fuerza un campo de "desórdenes" morales y sociales: vagancia, prostitución, alcoholismo, juegos de naipes, riñas de gallo. Moral y transgresión fueron entonces los pares articuladores de la coacción de las clases dominantes y de las resistencias de los sectores populares.

Pero la producción en/y sobre las regiones no alcanzó a cuestionar el acercamiento tradicional sobre los conflictos sociales articulados alrededor de las huelgas, que siguieron siendo claves para explicar las protestas regionales. En Tucumán fueron las huelgas azucareras las expresiones del conflicto laboral y social local y en Neuquén y Comodoro Rivadavia (Chubut) las huelgas petroleras. ${ }^{17}$

La actitud del Estado frente a la protesta obrera es otro de los temas que la historiografía ha tomado como relevante. La mayor parte de los trabajos se articula alrededor del eje represión e integración y muy pocos de ellos marcan las diferencias de género existente en los gestos estatales. ${ }^{18}$

A partir de fines de la década del sesenta emergieron movimientos de protestas que no sólo convocaban a los trabajadores industriales sino también a los vecinos de una comunidad y al movimiento estudiantil. Esas expresiones de protesta pueden designarse con el nombre de los "azos", porque las palabras que los designan se constituyen como adjetivos aumentativos que acrecientan la significación de la voces de las que proceden. Los primeros fueron el "cordobazo", el "viborazo" y el "rosariazo" y luego el "tucumanazo", "mendozazo", "choconazo", el "cutralcazo", y el "santiagueñazo". ${ }^{19}$ Algunas de ellas han dado lugar a un amplio debate historiográfico como el cordobazo, otras se encuentran en los textos militantes de

17 Santamaría, Daniel: Las huelgas azucareras de Tucumán, 1923, CEAL, Buenos Aires, 1984, Masés, Enrique et. al.: El mundo del trabajo: Neuquén 1884-1930, Neuquén, GEHiSo, 1994 y y Márquez, Daniel y Palma Godoy, Mario: Distinguir y comprender. Aportes para pensar la sociedad y la cultura en Patagonia, Comodoro Rivadavia (Chubut), Ediciones proyección patagónica, Comodoro Rivadavia (Chubut), 1995.

18 En particular véase Suriano, Juan (comp.): La cuestión social en Argentina, 1870-1943, Editorial La Colmena, Buenos Aires, 2000 y sobre las cuestiones de género los artículos de Mirta Zaida Lobato y Marcela Nari en el mismo volumen.

19 Entre otros se pueden citar: Crenzel, Emilio: El tucumanazo (1969-1974), 2 volúmenes, Buenos Aires, CEAL, Buenos Aires, 1991; Quintar, Juan: El choconazo, Educo, Buenos Aires, 1998. 
quienes las recuperan como parte de las luchas contra la injusticia y la opresión.

Los primeros "azos" fueron protestas que se originaron en el ciclo de rebeliones que estallaron en el interior del país al finalizar la década del sesenta. Desde el derrocamiento del peronismo la lucha de sindicatos y militantes peronistas se había desarrollado fuera de los marcos "legales" con la denominada "resistencia peronista". Durante los primeros gobiernos militares que sucedieron a Perón, en el gobierno desarrollista de Frondizi así como durante el breve gobierno de Illía, los dirigentes sindicales habían mantenido su poder y evitaron ser desbordados por las bases de sus gremios. Incluso la movilización y las huelgas fueron la base de sus continuas negociaciones con los poderes de turno.

Ya durante el gobierno militar de Onganía se intentó clausurar toda forma de acción gremial y política y, de ese modo, se abonó el terreno para diferentes protestas como el cordobazo. Esta movilización popular tuvo un efecto de demostración y se sucedieron alzamientos populares en las ciudades del interior, proliferaron las huelgas que desafiaban abiertamente a las direcciones sindicales nacionales y la protesta estudiantil ancló en las universidades. Ya en los años setenta, los "tumultos" de amplia base popular fueron perdiendo intensidad y frecuencia y el centro de la escena fue ocupado por la "guerrilla urbana". Los diferentes grupos armados - y no sólo ellos- compartían una "cultura de la rebelión" y confiaban en que los trabajadores estaban preparados para llevar a cabo la lucha decisiva por el poder. ${ }^{20}$

Con las profundas transformaciones que se produjeron en Argentina a partir de la última dictadura militar y durante los gobiernos democráticos posteriores emergieron nuevos actores, reclamos y formas de organización. La protesta central durante los años de la dictadura fue el movimiento por los derechos humanos, seguido por las movilizaciones barriales y la presencia de los sectores juveniles convocados por el rock "nacional". ${ }^{21}$

20 De Riz, Liliana: La política en suspenso, 1966/76, Paidós Buenos Aires, 2000.

21 Moreno, Oscar: "Apuntes para una discusión acerca de las nuevas formas de hacer política", en Oszlak, Oscar (compilador): "Proceso", crisis y transición democrática, vol. 2, Ceal, Buenos Aires, 1984; Jelin, Elizabeth (compiladora) (1987): Movimientos sociales y democracia emergente, 2 volúmenes, CEAL, Buenos Aires, 1987 y "Otros silencios, otras voces: el tiempo de la democratización en la Argentina", en Calderón Gutiérrez, Fernando (compilador), Los movimientos sociales ante la crisis, UNU, CLACSO, IISUNAM, Buenos Aires, 1986 y Thompson, Andrés: "Las luchas sociales en la Argentina (1976-1983), en Cheresky, Isidoro y Chonchol, Jacques (Compiladores): Crisis y transformación de los regímenes autoritarios, Eudeba, Buenos Aires, 1985. 
El aspecto más importante relacionado con la experiencia política en la última dictadura militar es que, al congelarse la vida sindical y política, la población diseñó formas no tradicionales de organización y participación. Se produjo un fenómeno de politización de lo cotidiano alrededor de las demandas de libertad, justicia, alimentación, vivienda, salud y educación. ${ }^{22}$

Hay cierto consenso en la historiografía alrededor de la importancia que fue adquiriendo en los "regímenes burocrático autoritarios", según la caracterización de O'Donnell, la coexistencia de viejas organizaciones de participación (por ejemplo sindicatos y partidos políticos) con la emergencia de otras nuevas. ${ }^{23}$

Ya durante los gobiernos democráticos de Raúl Alfonsin y en los períodos presididos por Carlos Saúl Menem otras formas de acción colectiva, como los saqueos y los cortes de ruta, dejaron al desnudo la crisis económica y política. ${ }^{24}$ En mayo de 1989 se incorporó al lenguaje de la protesta una nueva palabra: saqueos. Con ella se designa a una amplia y compleja trama de acciones que fueron desde la toma de alimentos que se consumían en el lugar de los saqueos, o eran transportados a las viviendas de los saqueadores, hasta la construcción de barricadas, apedreo de negocios, ataques a comisarías, marchas y choques callejeros entre saqueadores y policías, incluso el incendio de algunos comercios y la colocación de bombas de fabricación casera. ${ }^{25}$ La mayoría de las acciones se produjeron en localidades del Gran Buenos Aires (Quilmes, General Sarmiento, Moreno y Tres de Febrero) y en las ciudades de Rosario, Córdoba y Guaymallén en Mendoza, donde el peso de la población vinculada con las actividades industriales y comerciales era importante.

En cuanto a los cortes de rutas, ellos se convirtieron en un mecanismo para llamar la atención sobre el fenómeno de la desocupación en un contexto de fragmentación y reorganización del territorio y de sus proble-

22 Moreno: "Apuntes para una discusión...

23 Moreno: "Apuntes para una discusión..., García Delgado, D.R.: "Nuevos patrones de participación política en procesos de transición a la democracia: el caso argentino", en Oszlak (compilador): “Proceso”, Jelin, Movimientos sociales..., Thompson, "Las Luchas sociales...", 1986.

24 Véase las ponencias que se presentaron al taller/seminario organizado en la Universidad de General San Martín y publicado bajo el título "La protesta social en perspectiva", en Entrepasados, Revista de Historia, Año XI, Número 22, 2002.

25 Nicolás, Iñigo Carrera, et. al: La revuelta. Argentina 1989-90, Buenos Aires, PIMSA, Documentos de Trabajo 4, Buenos Aires, 1995 y 1997. 
mas ante los efectos negativos de la denominada globalización y de la aplicación de políticas neoliberales.

La ejecución de los planes privatizadores afectó seriamente las economías provinciales. En el caso de la provincia de Neuquén la privatización de la empresa estatal YPF (Yacimientos Petrolíferos Fiscales) ubicada en el área de Cutral-Co - Plaza Huincul llevó a la emergencia de movimientos de protesta: puebladas y cortes de ruta. ${ }^{26}$ Cuando en junio de 1996 se produjo el corte de la ruta 22 quienes ejercieron la custodia de las barricadas recibieron el nombre de "piqueteros". Desde entonces en forma creciente la interrupción del tránsito en las carreteras se transformó en la principal forma de protesta.

En los cortes de ruta se levantaron (y se levantan) barricadas con neumáticos encendidos lo que permite visualizar y definir un nuevo escenario para los conflictos. Los movimientos de protestas ya no se localizan en las fábricas y en sus adyacencias como en el pasado. Se trata de protestas en regiones alejadas del centro político de la ciudad de Buenos Aires, en uno y otro extremo del país. Según información periodística en 1997 se realizaron 140 cortes de ruta en todo el país, en 1998 se redujeron a 51, para elevarse en 1999 a 252. La profundización de la crisis económica se refleja en las cifras del año 2000: 514 cortes de ruta. ${ }^{27}$ En las protestas participan las familias enteras, las mujeres organizan las "ollas populares", los niños y jóvenes alimentan el fuego de las barricadas. En el lugar se realizan las asambleas en donde se escucha la opinión de los participantes y se votan las decisiones. Estamos asistiendo, entonces, no sólo a la configuración de un nuevo modo de protesta sino también a transformaciones en el nivel de organización y demandas de los desocupados. ${ }^{28}$

Hasta aquí todos los conflictos tienen su origen en el mundo del trabajo (o en su ausencia si se considera la protesta contemporánea) en un sentido estricto. Sin embargo el campo del consumo o de la vida cotidiana queda abierto aún a posibles exploraciones. Juan Suriano analizó la huelga de inquilinos de 1907 como parte de un movimiento de consumidores y como el resultado de las particulares condiciones de vida de los sectores popula-

26 Favaro, Orietta, Arias Bucciarelli, Mario e Ivorno, Graciela: "Políticas de ajuste, protestas y resistencias. Las puebladas cutralquenses", en Favaro Orietta: Neuquén. La construcción de un orden estatal, Cehepyc, Neuquén, 1999, Sánchez Pilar: El cutralcazo. La pueblada de Cutral Co y Plaza Huincul, Agora., 1997 y Ogando, Ariel: "Desocupados y cortes de ruta en el noroeste argentino", en Herramienta, revista de debate y crítica marxista, N. ${ }^{\circ}$ 15, Año V, Buenos Aires, 2001.

27 Clarín, 24 de junio de 2001.

28 Clarín, 1 al 4 de septiembre de 2002. 
res en el Buenos Aires de principios de siglo. ${ }^{29}$ En efecto las condiciones de la vivienda urbana y el incremento de la renta de los alquileres fue el motor de una protesta en la que mujeres y niños cumplieron un papel preponderante. La negativa a pagar los alquileres le dio mayor visibilidad a una situación a la que el Estado había permanecido indiferente.

\section{Las fuentes}

Hay fuentes que hoy podríamos catalogar como tradicionales y que han sido profusamente utilizadas por los estudiosos de los trabajadores y de las protestas en Argentina. La información producida por las instituciones estatales han sido transitadas una y otra vez. Así los informes oficiales sobre la situación de las clases laboriosas tanto en el interior del país (Informe Bialet Massé) como en la Capital Federal (Informe Storni, más los boletines e investigaciones del Departamento Nacional del Trabajo hasta su transformación en Secretaría de Trabajo y Previsión luego del golpe militar del 4 de junio de 1943 fueron fuentes importantes, aunque no suficientemente explotadas.

Lo mismo puede decirse de la prensa en general, tanto la anarquista, socialista y comunista como la de las grandes empresas periodísticas, incluso la existente en las ciudades del interior. Los periódicos gremiales son menos consultados, a veces porque resulta difícil localizarlos en el país o por la escasez de recursos para realizar las copias de los materiales existentes en el exterior como la del Instituto de Historia Social de Amsterdan.

El uso de fuentes alternativas, como en documentos orales, se ha extendido recién en las últimas décadas. Como ha sucedido en el movimiento de historia oral en otros países, el punto de partida de esta corriente fue suplir el silencio de las fuentes escritas y "darle voz a los sin voz", luego se orientó a leer los síntomas que aparecían en la narración. Ellos se revelaron como una meta más rica y matizada, sobre todo porque permitía establecer la relación de los trabajadores con una cosmovisión y un campo cultural en el cual los hombres y mujeres vivían su historia. En los últimos años la mayoría de los trabajos se concentraron en analizar temas que relacionaban memoria e identidad. Las investigaciones que se refieren a la

29 Suriano, Juan: La huelga de inquilinos de 1907, CEAL, Buenos Aires, 1983. 
experiencia de trabajo, protesta y organización de los años setenta han utilizado los testimonios orales más como un gesto simbólico de otorgar la voz a la gente común que como parte de un trabajo atento a los síntomas conflictivos que aparecen en los relatos..$^{30}$

Por otra parte, desde el punto de vista estadístico es difícil hacer una reconstrucción de las formas y ciclos de protesta. La información es insuficiente, fragmentaria y heterogénea aunque es cierto que algunos estudiosos han intentado cuantificar el número de conflictos que se produjeron en el mundo del trabajo, sobre todo para la segunda mitad del siglo XX. ${ }^{31}$

\section{Los debates}

En Argentina no hay una fuerte tradición de debates historiográficos. Por diversas razones cuya explicación escapa a este texto las confrontaciones académicas y las polémicas alrededor del pasado no han tenido la virulencia que a veces adquirieron en otros países. Las divergencias sobre la caracterización de un conflicto derivaron muchas veces de combates políticos partidarios y lo que se estaba discutiendo era la corrección o no de las posturas de un partido político determinado.

Sin embargo, algunas controversias se han generado alrededor del papel de las huelgas que tuvieron lugar en determinadas coyunturas. El carácter de las huelgas, su intensidad y la persistencia a lo largo del tiempo ha dado lugar a una caracterización de la identidad y de la cultura obrera que iría de una mayor radicalización a principios de siglo a una creciente pasividad e interés por la negociación en el período de entreguerra.

Los trabajos que analizan esta situación lo hacen desde distintos puntos de partida. Están aquellos que preocupados por la relación estado-sindicatos, en particular durante el peronismo, enfatizan los elementos de continuidad entre los comportamientos obreros en la década del treinta y la siguiente marcada por la relación con Perón. En este punto la declinación de las huelgas generales no era un síntoma de la disminución o el amortiguamiento de la conflictividad obrera sino que tenían lugar otras manifes-

30 Lobato, Mirta Zaida: La vida en las fábricas. Trabajo, protesta y política en una comunidad obrera, Berisso, 1904-1970, Prometeo libros-Entrepasados, Buenos Aires, 2001.

31 Korzeniewics, Roberto P.: "Labor unrest in Argentina, 1930-1943", en Latin American Research Review, vol. 28 N. ${ }^{\circ}$ 1, 1993 y McGuire, James W.: "Strikes in Argentina: Data sources and recent trends", en Latin American Research Review, Vol. 31, N. ' 3, 1996. 
taciones como huelgas parciales. En realidad se producían conflictos que terminaban en una negociación o acuerdos con los patrones. ${ }^{32}$

Lo cierto es que en las cuatro primeras décadas del siglo XX se extendieron los conflictos laborales (huelgas parciales y huelgas generales, huelgas de brazos caídos, trabajo a desgano, trabajo a reglamento, paros de unos pocos minutos por turno de trabajo) y los trabajadores adoptaron de manera amplia diversas formas de acción colectiva y presionaron sobre el Estado y los patrones para lograr sus demandas..$^{33}$ Sin duda esas acciones excedieron a las huelgas que, como manifestaciones de protesta, quedaron registradas en las estadísticas oficiales. Por eso, cualquier examen sobre las manifestaciones del conflicto laboral y social en la Argentina requiere de una búsqueda amplia de la información en diversos tipos de fuentes.

Desde otra perspectiva Gutiérrez y Romero han propuesto la existencia de dos grandes identidades sucesivas entre los sectores populares de Buenos Aires entre 1880 y 1940: una trabajadora y contestaria, fuertemente influida por el anarquismo, y otra popular, conformista y reformista, con influencia del socialismo. ${ }^{34}$ Aunque reconozco los impulsos a la investigación que las ideas de ambos historiadores generaron, tanto porque concitaban un amplio consenso en investigaciones que querían abarcar a un conjunto más vasto de actores que fueron englobados con el nombre de "sectores populares" como por las críticas de quienes encontraban (encontrábamos) que la noción desdibujaba la necesidad de investigar en profundidad sobre la condición obrera en la Argentina, la idea de sucesión de identidades resulta una interpretación esquemática y sugiere un proceso evolucionista aunque probablemente no necesariamente progresista ( $; \mathrm{se}$ atribuye algún valor a las palabras identidad contestaria e identidad reformista?). Por otra parte la conformación de esas identidades no da cuenta

32 Del Campo, Hugo: Sindicalismo y peronismo. Los comienzos de un vínculo perdurable, CLACSO, Buenos Aires, 1983, Gaudio, Ricardo y Pilone, Jorge: "El desarrollo de la negociación colectiva durante la etapa de modernización industrial en la Argentina, 1935-1943", en Desarrollo Económico, v.23, N. ${ }^{\circ}$ 90, Buenos Aires, julio-septiembre de 1983 y Gaudio, Ricardo y Pilone, Jorge: "Estado y relaciones laborales en el período previo al surgimiento del peronismo, 1935-1943", en Desarrollo Económico, v.24, N. ${ }^{\circ}$ 94, Buenos Aires, julio-septiembre de 1984 (también en Juan Carlos Torre (compilador): La formación del sindicalismo peronista, Legasa, Buenos Aires, 1988).

33 Del Campo: Sindicalismo y peronismo ..., Horowitz, Joel: Argentine Unions, the State \& the rise of Peron, 1930-1945, IIS, Berkely, 1990, Lobato: La vida en las fábricas... y Matsushita, Hiroschi: Movimiento obrero argentino 1930-1945. Sus proyecciones en los orígenes del peronismo, Siglo Veinte, Buenos Aires, 1983.

34 Gutiérrez, Leandro y Romero Luis Alberto: Sectores populares cultura y política. Buenos Aires en la entreguerra, Sudamericana, Buenos Aires, 1995. 
de las profundas transformaciones en el plano de las ideologías que significó la emergencia del comunismo y su influencia, tan parcial como la socialista y la anarquista, entre los trabajadores. Cabe preguntarse también cuál de las dos caracterizaciones serían más adecuadas en el caso del comunismo, y queda pendiente una exégesis de las propias nociones de contestación y reforma entendidas como categorías explicativas que se construyen históricamente.

La visión sobre las identidades que se moldearon en Argentina en las primeras décadas del siglo XX tiene un corolario adicional. Para Gutiérrez y Romero los sectores populares no establecieron una relación directa entre reivindicaciones económicas y ejercicio de la ciudadanía. Para ellos, como para Germani, la integración de los sectores populares era un requisito imprescindible de la conformación de una democracia y no se amalgamaron la construcción de las ciudadanías política y social. Sin embargo es importante considerar el modo en que los trabajadores entendieron que funcionaba la vida política, tanto la formal, organizada alrededor de los partidos políticos, como la informal canalizada por diferentes organizaciones y manifestaciones. El estudio más acotado del espacio fabril muestra los límites de la relación trabajadores-sindicatos-partidos así como las dificultades para la conformación de una democracia en términos equitativos y más distributivos en la Argentina, aunque esto no significa que los trabajadores no lucharan por sus derechos. ${ }^{35}$

En cuanto a las huelgas las que realmente llamaron la atención de los estudiosos fueron aquellas que se produjeron acompañadas por actos de violencia colectiva. Hay algunas fechas que han servido para analizar cuáles fueron esas manifestaciones de violencia y porqué se produjeron en esos momentos y no en otros. La semana roja (1909), la semana trágica (1919), el 17 de octubre (1945), el cordobazo ( mayo de 1969) son algunas de las denominaciones y sus fechas. Cada uno de estos momentos ha dado lugar a un debate específico, salvo el caso de la semana roja de 1909 que recibió escasa atención hasta la aparición de un texto donde se realiza un examen minucioso de las causas de la huelga y la violencia, de la represión policial, de la reacción de los trabajadores y del papel de la prensa escrita pero ese análisis no ha dado lugar a un debate todavía ${ }^{36}$ La huelga general de 1909 fue una "evidente expresión de la protesta social de la clase obre-

35 Lobato: La vida en las fábricas...

36 Frydenberg, Julio y Ruffo, Miguel: La semana roja de 1909, CEAL, Buenos Aires, 1992. 
ra" y ella estaba dirigida contra los "crímenes policiales". Era un síntoma de los trastornos de la sociedad argentina del período, cuya conflictividad es ignorada muchas veces por la historiografía que analiza este momento como una etapa dorada del pasado.

En contraposición el debate en torno a la semana trágica de 1919 recorta dos formas de hacer historia. Julio Godio, parte del análisis de las ideologías dominantes en el seno del movimiento obrero y trata de desentrañar las cuestiones vinculadas con la ausencia de un modelo revolucionario así como encontrar una guía para la acción. ${ }^{37} \mathrm{El}$ "clima de ideas" de los años setenta está marcado por el privilegio de la violencia como forma de acción política y Godio encuentra en los trabajadores de la fabrica Vasena y en sus protestas un ejemplo de la simpatía que tenían los trabajadores por la acción directa. "Estas formas embrionarias de lucha armada - dice Godio- demostraban que eran exclusivamente encabezadas por grupos restringidos; la enorme masa que había participado en el cortejo fúnebre, continuaba dispuesta a proseguir la huelga y exasperada por las nuevas matanzas, pero estaba marginada en las nuevas operaciones llevadas a cabo por estos grupos selectos" ${ }^{38} \mathrm{Si}$ volver la vista hacia el pasado es un ejercicio cotidiano de los historiadores, Julio Godio no podía desprenderse del tono de su época para interrogar estos acontecimientos. Por eso concluía que "el gobierno, aunque los conservadores lo acusasen de 'pusilánime", comprendía claramente el peligro de que la huelga pudiese transformarse en un movimiento de tipo insurreccional". ${ }^{39}$ Para Godio, al advertir el estado liberal que estaba amenazado por la posibilidad de la insurrección sólo le quedaba el ejército y las organizaciones paramilitares (civiles armados) para enfrentar la amenaza maximalista. En su momento David Rock debatió las tesis de Godio sobre la semana trágica. Para él nada había del movimiento insurreccional que señalaba Godio. La protesta masiva constituía un estallido emocional masivo, sin coordinación, ni dirección por lo que no podía ser interpretado como una anticipación de la lucha armada moderna ${ }^{40} \mathrm{El}$ debate quedó congelado y el trabajo de Edgardo Bilsky, quien considera a los acontecimientos del

37 Godio, Julio: La semana trágica de 1919, Graniza, Buenos Aires, 1972.

38 Godio: La semana trágica de 1919..., pág. 36.

39 Godio: La semana trágica de 1919..., pág. 38.

40 Rock, David, Rock: "La semana trágica y los usos de la historia", en Desarrollo Económico, N. ${ }^{\circ} 45$, Buenos Aires, 1972 y "Lucha civil en la Argentina. La semana trágica de 1919", en Desarrollo Económico, 11, 42-44, Buenos Aires, 1972. 
año 1919 como el fin de una etapa insurreccionalista y se basa en una amplia documentación, no alcanzó para modificar o reorientar las bases de la discusión. ${ }^{41}$

Mas fructífera fue la línea de debate abierta sobre el peronismo y en particular sobre la movilización obrera de $1945 .{ }^{42}$ Así, si hubo consenso en las investigaciones sobre las manifestaciones de violencia que acompañaron la movilización obrera en defensa de Perón, algunos la vieron como expresión de la movilización espontánea de masas susceptibles de ser manipuladas; ${ }^{43}$ en otros casos se enfatizó el papel de las viejas dirigencias gremiales en la organización del paro y de la protesta, ${ }^{44}$ y otros investigadores enfatizaron los elementos disruptivos (contrateatro) de los trabajadores. ${ }^{45}$

En estrecha relación con el peronismo como movimiento político y gremial se produce un desplazamiento del interés de los estudiosos hacia la década del treinta. El período que se extiende desde el estallido de la crisis económica y el golpe militar de 1930 hasta el ascenso del peronismo en 1945 fue visto frecuentemente a partir del punto de llegada que significaron la primera y segunda presidencia de Juan Domingo Perón, sólo recientemente algunos estudios se concentran en la especificidad del período pero no refieren a la protesta.

De la primera de las corrientes mencionadas, los trabajos de Gaudio y Pilone colocan en la mesa de debate un aspecto importante sobre el desarrollo del conflicto y la negociación colectiva en esta etapa. Al discutir la idea de un estado no intervensionista en materia laboral antes de Perón colocaron la acción de la clase obrera en el centro de los acontecimientos que impulsaron los procesos de conflicto y negociación de la época. Para ellos, el proceso de negociación colectiva que involucró a trabajadores, empresarios y Estado fue el resultado de la "intensidad y difusión alcanzada por la movilización y los conflictos laborales que acompañaron la reactivación del ciclo económico experimentado desde 1935" ${ }^{46}$

41 Bilsky, Edgardo: La semana trágica, CEAL, Buenos Aires, 1984.

42 Torre, Juan Carlos (comp.): El 17 de octubre de 1945, Ariel, Buenos Aires, 1995.

43 Germani: Política y sociedad...

44 Torre, Juan Carlos: La vieja guardia sindica y Perón. Sobre los orígenes del peronismo, Sudamericana, Buenos Aires, 1990.

45 James: Resistencia en Integración... y "17 y 18 de octubre de 1945: el peronismo, la protesta de masas y las clase obrera argentina", en Desarrollo Económico, N. ${ }^{\circ} 107$, vol. 27, octubrediciembre, 1987.

46 Gaudio y Pilone: "Estado y relaciones laborales... 
De manera que dividen el período en dos etapas claramente diferenciadas. La primera, de 1930 a 1934, se distinguiría por la tendencia decreciente a la movilización acorde con las dificultades que planteaba la crisis económica; la segunda se extendería desde mediados de la década, cuando al reactivarse la economía se promovió también la ocupación "robusteciendo la capacidad de negociación del sindicalismo". Los numerosos conflictos se resolvieron negociando lo que se hizo visible en el número de huelgas ganadas y transigidas.

Sobre la etapa peronista hay un sentido fuertemente consolidado en la población trabajadora de que "en época de Perón [todo]era una hermosura", sin embargo, la historiografía muestra más matices. Louise Doyon señaló que durante 1945 y 1955 no sólo se multiplicaron las protestas de los trabajadores protagonizadas por los opositores como por las bases peronistas. ${ }^{47}$ Mucho tiempo después he demostrado las características del trabajo y de las protestas en esta etapa marcando la intensidad y la variedad de los conflictos que se producían en los frigoríficos de capital norteamericano. Los trabajadores de la carne se habían movilizado por Perón el 17 de octubre de 1945 pero su experiencia de movilización y participación se había conformado en la etapa previa bajo la dirección de los comunistas quienes tras las confrontaciones del período 1943-46 había sido desalojado de las organizaciones sindicales. ${ }^{48} \mathrm{Al}$ mismo tiempo, los paros parciales por turno y las huelgas de brazos caídos preocuparon enormemente a las direcciones gremiales que trataron de ordenar y orientar las modalidades y oportunidades de la protesta. Pero el análisis de los trabajos mencionados se concentra en las protestas de los obreros industriales. Una vez más, poco se sabe de lo que sucedía en el campo durante los años peronistas.

Sobre la conflictividad rural para el período agroexportador Ezequiel Gallo ha estudiado una amplia gama de tensiones que afectaron la zonas santafecinas bajo colonización, algunas de las cuales pueden extenderse al territorio de La Pampa. ${ }^{49} \mathrm{La}$ inseguridad de las fronteras por los avances indígenas, la exposición a los bandidos rurales y la resistencia frente a los abusos de las autoridades se menciona entre los más frecuentes y casi cotidianos problemas que afectaban a los colonos. Otras líneas de

47 Doyon, Louise: “ Conflictos obreros durante el régimen peronista (1946-1955)," en Desarrollo Económico, v. 17, N. ${ }^{\circ}$ 67, Buenos Aires, octubre-diciembre de 1977, (también en Torre (compilador), La formación del sindicalismo peronista...).

48 Lobato: La vida en las fábricas ...

49 Gallo, Ezequiel: La pampa gringa, Sudamericana, Buenos Aires, 1983. 
tensión se alimentaban con los roces diarios con las autoridades pero estallaban en coyunturas particulares. La oposición al juez de paz o a los jefes políticos locales emergieron durante toda la década del setenta del siglo XIX y, en los años noventa, los colonos santafecinos volvieron a protestar cuando estaba concluyendo una fase económica de prosperidad que se extendió entre 1878 y 1893. La movilización se extendió a todas las colonias y la represión contra los rebeldes fue en algunos casos feroz. Las demandas de los colonos eran modestas. Reclamaban la eliminación o la disminución de los gravámenes fiscales que pesaban sobre la producción y la comercialización de sus productos. No discutieron ni la política oficial de tierras, ni la situación de los arrendamientos, ni la de los trabajadores rurales.

Los problemas existentes en el mundo rural pampeano afloraron nuevamente en la década del diez en el territorio nacional de La Pampa. Allí, los chacareros de Macachín y Colonia Trenel se organizaron y movilizaron reclamando la abolición de los contratos expoliadores y de la práctica de los pagarés en blanco. El movimiento fue violentamente reprimido, se produjeron detenciones y algunas muertes. Pero es el Grito de Alcorta que se extendió por la zona maicera del sur santafecino, el este de Córdoba y el norte de Buenos Aires, el movimiento que colocó en la escena pública el potencial conflictivo existente en el campo. Según Aníbal Arcondo $^{50}$ la coyuntura (recordemos la importancia que le asignan Laclau y Sabato para la emergencia de conflictos sociales) fue el inflamante: elevados cánones de renta de tierra y la baja circunstancial del precio del maíz y el arrastre del endeudamiento por la mala cosecha del año agrícola anterior. El interés de Arcondo era discutir claramente las caracterizaciones que hacía la historiografía "tradicional" de la protesta, representada por el libro pionero de Plácido Grela,$^{51}$ quien se refería al movimiento rural como una huelga ("la huelga de arados") así como enfatizaba los fenómenos ideológicos en el desarrollo de la protesta. Para Grela se trataba de un clásico enfrentamiento de clase. Para Arcondo sólo era una discusión coyuntural sobre la cuota parte de lo producido.

Las protestas de los años sesenta y setenta han dado lugar a otro núcleo importante de divergencias historiográficas. El cordobazo despertó enormes expectativas sobre las posibilidades de cambio social que podía

50 Arcondo, Aníbal: "El conflicto agrario argentino de 1912. Ensayo de interpretación”, en Desarrollo Económico, vol. 20, N. ${ }^{\text {7 } 79, ~ B u e n o s ~ A i r e s, ~ o c t u b r e-d i c i e m b r e d e ~} 1980$.

51 Grela, Plácido: El grito de Alcorta, CEAL, Buenos Aires, 1985. 
generarse. El texto que mejor muestra la amplitud de las expectativas (y de las simpatías) que despertó es el de Beba Balve. Allí se sostiene que los conflictos de mayo de 1969 y marzo de 1971 en Córdoba "son parte del proceso de ascenso de las masas obreras y populares, en un largo camino estratégico - de avances y repliegues-, hacia el socialismo hegemonizado por el proletariado". ${ }^{52}$ Para ellos era "la lucha de calles" como nueva forma de enfrentamiento social lo que consideraban el elemento fundamental y distintivo de la lucha de clases en la Argentina .

Era la novedad de la movilización popular lo que llamaba la atención en ese momento. Así en la primera edición de Crisis y protesta social, Francisco Delich enfatizaba que la Argentina no había sido pródiga en "movimientos sociales violentos" que "hayan producido modificaciones sustanciales en el sistema de relaciones sociales" y que el análisis del cordobazo como acción social estrechamente relacionada con el sistema socioeconómico permite ahondar en la "teoría de los movimientos sociales". Y esto era así porque el cordobazo no era solamente una acción obrera. Delich señala los hechos sobre el que construirá sus interpretaciones y sobre los que se edificarán algunas lecturas posteriores. ${ }^{53}$

De manera esquemática se puede sintetizar que esas observaciones refieren a los actores de la protesta y a algunas de sus características: 1) los elementos más activos de la movilización fueron los obreros y los estudiantes que encuentran rápido eco en las clases medias; 2) la acción se extendió por toda la ciudad de Córdoba; 3 ) las organizaciones estudiantiles y obreras fueron desbordadas; 4) los partidos políticos tradicionales no tuvieron injerencia en la manifestación (fueron marginados); 5) el lenguaje de la movilización fue el de los hechos mismos (no hay lemas pintados en las paredes); 6) no hay una estrategia visible de la guerrilla detrás de los francotiradores que, por otra parte, no tiran a matar y 7) no hubo saqueo ni pillaje en la ciudad.

Con escasas variantes esas características se identifican en otras manifestaciones colectivas en ciudades como Rosario, Tucumán y Mendoza. En algunos casos se trataba de protestas que habían surgido a partir de los conflictos suscitados en una actividad industrial (los trabajadores mecánicos del Smata y los de Luz y Fuerza en Córdoba, los trabajadores de la cons-

52 Balvé, Beba et. al: Lucha de calles y lucha de clases elementos para su análisis (Córdoba 1971-1969), La rosa blindada, Buenos Aires, 1973, pág. 199.

53 Delich, Francisco: Crisis y protesta social. Córdoba 1969, Fundación de la Universidad Nacional de Córdoba.CEA, Córdoba, 1994. (La primera edición es de 1970). 
trucción en el Chocón- Río Negro y los de los ingenios azucareros en la provincia de Tucumán; en otros, las protestas se vinculan con las de los empleados del estado (docentes en Mendoza y empleados públicos en Santiago del Estero).

Lo llamativo de estos movimientos (los "azos") era la masiva participación de capas más amplias de la sociedad y del movimiento estudiantil. Esta participación no sólo se había producido en la ciudad de Córdoba donde existía una tradición de movilización de los estudiantes universitarios alimentada desde las jornadas de 1918, también se produjeron en Rosario y en Corrientes y se expresaba a través de marchas, asambleas, concentraciones y tomas de facultades. La movilización se había producido tras la intervención a las universidades públicas por el gobierno de Onganía en 1966, lo que violaba la autonomía de esas instituciones de educación superior. Los estudiantes le decían "no" a la intervención y reclamaban el ingreso sin restricciones a la universidad.

Más recientemente Mónica Gordillo ${ }^{54}$ y James Brennan ${ }^{55}$ han reflexionado tanto sobre el cordobazo como sobre el ciclo de protesta obrera que se produjo en Córdoba entre 1969 y 1971 como base para la construcción de un movimiento social. Específicamente. Gordillo sostiene que la movilización local basada en demandas particulares irían paulatinamente cuestionando el régimen político y comprometiendo de diferentes maneras a distintos actores sociales. La "estructura de oportunidad política" favoreció su conformación como movimiento que atrajo la solidaridad de intelectuales progresistas, profesionales aliados, estudiantes, sectores de la Iglesia y de la prensa local que reprodujo y reforzó ciertos imaginarios que promovían el cambio. Paralelamente se utilizaron diferentes estructuras para la movilización, desde las formales (sindicatos) hasta las informales (redes sociales barriales por ejemplo) que ayudaron a sostener el movimiento. Desde este punto de vista, con los "azos" estaríamos en presencia de cambios en los repertorios de confrontación pues se incorporaban nuevos actores (los estudiantes, los vecinos, por ejemplo) y mecanismos informales que revitalizaban los movimientos de protestas.

54 Gordillo, Mónica: "Movimiento sociales e identidades colectivas, repensando el ciclo de protesta obrera", en Desarrollo Económico, N. ' 155, Vol. 39, Buenos Aires, octubre.diciembre de 1999 y Córdoba en los '60. La experiencia del sindicalismo combativo, Universidad Nacional de Córdoba, Córdoba, 1996.

55 Brennan, James: El Cordobazo. Las guerras obreras en Córdoba, 1955-76, Sudamericana, Buenos Aires, 1996. 
La protesta más reciente, aquella que tuvo lugar con los saqueos, cortes de ruta, cacerolazos y asambleas vecinales recién está siendo estudiada, pero ya pueden enunciarse alguno de los temas en debate: el papel de las reformas neoliberales en el surgimiento de las manifestaciones de desocupados/piqueteros y en la movilización de las clases medias; el carácter espontáneo o no de los saqueos; los vínculos existentes entre protesta y ciudadanía en un país con una fuerte crisis de representación de los partidos políticos; el papel de los medios de comunicación, sobre todo para legitimar o no las acciones colectivas; la ruptura de las viejas identidades políticas (el peronismo por ejemplo) y la formación de otras nuevas.

\section{Un epílogo posible}

Esta somera revisión de la protesta social en Argentina, en particular de las clases populares, muestra que la producción historiográfica existente es todavía insuficiente para diseñar un cuadro de los conflictos que se han producido a lo largo del siglo XX. Son numerosas las cuestiones que quedan al margen de las investigaciones analizadas: desde las formas de protesta como el boicot y el sabotaje hasta las particularidades regionales. También, y aunque parezca reiterativo, la protesta rural sigue siendo la gran ausente $y$, si efectivamente es lo que distingue a nuestro país necesitamos algunas explicaciones, salvo que los argumentos de Jorge Sabato o Ernesto Laclau puedan extenderse para todo el siglo XX lo que resulta poco convincente.

Para la primera mitad del siglo XIX no hay todavía una explicación convincente de las formas que adquirió la protesta social o de su debilidad. No quisiera ser injusta con la extensa literatura sobre el mundo rural y sobre la historia política del período pues ciertamente se realizó una profunda revisión de algunos temas y aunque las estancias y parajes fueron visitados una y otra vez y se analizaron diferentes explotaciones el cuadro más intensamente dibujado es el de la generalización de las relaciones salariales y de las dificultades de las clases propietarias para resolver la fuerte escasez de trabajadores. ${ }^{56}$

56 Garavaglia, Juan Carlos: "'Pobres y ricos'; cuatro historias edificantes sobre el conflicto social en la campaña bonaerense (1820-1840), Entrepasados, Revista de Historia, N. ${ }^{\circ}$ 15, Buenos Aires,1998 y Gelman, Jorge: "Las condiciones del crecimiento estanciero en el Buenos Aires de la primera mitad del siglo XIX. Trabajo, salarios y conflictos en las estancias de Rosas", en Jorge Gelman, Juan Carlos Garavaglia y Blanca Zeberio (comp.): Expansión capitalista y transformaciones regionales. Relaciones sociales y empresas agrarias en la Argentina del siglo XIX, La Colmena, Buenos Aires, 1999. 
La resistencia a "conchabarse" aparece como uno de los clásicos conflictos de la campaña bonaerense y cobra cuerpo en una extensa literatu$\mathrm{ra}$, pero esa resistencia no ha dado lugar a manifestaciones de protesta con un alto grado de visibilidad. Desde una perspectiva que coloque el foco de análisis en los sectores populares los desafíos a las elites o a la autoridad se presenta como poco conflictiva. Y lo que resulta más llamativo aún es la escasa relación que se establece en los trabajos históricos sobre las acciones violentas y los conflictos en el plano político con la dimensión de lo social. Al margen de esta caracterización se encuentra el trabajo de Pilar González Bernaldo sobre la importante movilización rural de 1829 en la provincia de Buenos Aires, que fue estudiada tradicionalmente como parte de un conflicto político que enfrentaba a Juan Manuel de Rosas y Juan Lavalle. ${ }^{57}$

González Bernaldo señala que fue una movilización protagonizada por diferentes agentes: tribus indígenas que vivían al margen de la sociedad blanca, gauchos seminómades que poblaban la frontera y gauchos soldados todos ellos vulnerables ante la ley y, de algún modo, conscientes de las injusticias y desigualdades frente a ella. Destaca también que la movilización y el descontento en la campaña fue el resultado de las transformaciones de la estructura productiva, los problemas generados por la guerra con el Brasil (1825-1828) que acentuó el proceso inflacionario y generó una contracción de la actividad de los saladeros y la reactualización de la ley de milicias de 1823 y de las leyes sobre "vagos y mal entretenidos". De modo que une la situación económica con la coyuntura política y la indignación social y, por eso se constituye en la contracara de aquellas investigaciones que levantan barreras importantes entre los niveles político y social.

Por otra parte quedan también al margen otras manifestaciones de protestas que son importantes pero escapan del cuadro de los conflictos urbanos analizados en la literatura específica. Cualquier análisis de las protestas desde una perspectiva más amplia termina desbordando las formas del conflicto en las ciudades, principalmente las del litoral. Los matices cobran fuerza cuando se consideran otros actores, escenarios y origen de los reclamos. Por ejemplo resultan atractivos conflictos como la resistencia campesina de 1874 en la Puna jujeña para reclamar la propiedad de las tie-

57 González Bernaldo, Pilar: "El levantamiento de 1829: el imaginario social y sus implicaciones políticas en un conflicto rural”, en Anuario IEHS, N. ${ }^{\circ}$, Tandil Universidad Nacional del Centro de la Provincia de Buenos Aires, 1987. 
rras ${ }^{58}$ los levantamientos nativistas y contra los gringos ocurridos en Tucumán en 1886 asociados con las transformaciones provocadas por el desarrollo de la industria azucarera y una epidemia de cólera ${ }^{59}$ el movimiento milenarista de 1872 en Tandil ${ }^{60}$ y las protestas de los indígenas mocovíes de 1904, 1924 y 1933. Bajo la influencia de Eric Hobsbawn algunos autores han enfatizado el carácter primitivo de estas rebeliones y muchas veces se los lee como curiosas supervivencias del pasado. Sin embargo esas expresiones de protestas no eran movimientos teñidos de primitivismo, por lo contrario eran los síntomas de un complejo juego de relaciones y conflictos en un momento de cambios vertiginosos.

En síntesis lo que muestra la literatura analizada es la importancia que adquirió a partir de 1880 la huelga como forma de protesta en estrecha relación con la experiencia del trabajo. La huelga fue la herramienta clave de la confrontación tanto en una etapa en que los trabajadores actuaban defensivamente como en aquellos períodos en que fueron considerados interlocutores legítimos en el proceso político y social.

La huelga entendida como arma económica y política de los trabajadores fue el foco de un debate amplio que involucró a los historiadores que habían encontrado en los escritos de Marx el reconocimiento de la importancia de la solidaridad en las acciones colectivas que se habían producido en Inglaterra y Francia. Los historiadores de los conflictos sociales en Argentina hallaron en el trabajo en fábricas y talleres la materia que permitía dar forma a las organizaciones y a la acción colectiva. Por eso el foco ilumina las huelgas y los debates alrededor de su desarrollo e importancia. En este punto habría que señalar que, tanto en el debate de las organizaciones obreras de la primera mitad del siglo XX, como en el de los historiadores que estudiaron la "semana trágica" y el "cordobazo", está presente la discusión sobre la huelga que tuvo lugar entre los militantes de la Segunda Internacional y dentro de la social democracia alemana y, sobre todo, alrededor de la experiencia de la huelga general belga de $1902 .{ }^{61}$

58 Paz Gustavo: "Resistencia y rebelión campesina en la Puna de Jujuy, 1850-1875", en Boletín del Instituto de Historia Argentina y Americana “Dr. E. Ravignani”, N. o 4, Buenos Aires, 1991.

59 Goldman, Noemí: "El levantamiento de montoneras contra 'gringos' y 'masones' en Tucumán, 1887: tradición oral y cultura popular", en Boletín del Instituto de Historia Argentina y Americana Dr. Emilio Ravignani, N. ${ }^{\circ}$ 3, Buenos Aires, 1990.

60 Nario, Hugo: Tata Dios. El mesías de la última montonera, Buenos Aires, Plus Ultra, Buenos Aires, 1976 y Los crímenes del Tandil, 1872, Ceal, Buenos Aires, 1985.

61 El debate puede seguirse en Parvus, Frölich, Vandervelde, Mehring, Luxemburg, Kautsky: Debate sobre la huelga de masas, Cuadernos de Pasado y Presente, 62, México, 1978. 
La importancia de la huelga como forma de acción colectiva obrera se mantuvo a lo largo del siglo XX pero se rebeló como insuficiente para hacer oír las demandas cuando las profundas transformaciones económicas que se produjeron en el país erosionaron el trabajo fabril y el poder de las organizaciones sindicales. Cuando las organizaciones gremiales se mostraron como limitadas para la defensa de los intereses de los trabajadores, no sólo porque el crecimiento de la desocupación fue limitando su poder de convocatoria sino también porque su relación tan estrecha con el gobierno justicialista —en particular durante los diez años de gobierno del presidente Carlos S. Menen-, se fue generando, al mismo tiempo, desconfianza en la población trabajadora como desprestigio por su falta de reacción, cuando no complicidad, con la ejecución de las políticas neoliberales. Los repertorios de confrontación tradicionales eran insuficientes y la población tuvo que imaginar otros canales de acción: se organizaron marchas de silencio, apagones y particularmente se generalizaron los cortes de ruta. Impedir el tránsito vehicular pareció una herramienta eficaz a la hora de convertir en público el drama que la desocupación o la falta de inversión en "bienestar" habían provocado.

Si los repertorios de confrontación cambiaron a lo largo de los siglos XIX y XX hay un elemento que se mantiene casi inalterable: la violencia. En principio, porque los grupos dominantes no reconocieron los derechos de la población sin la presión que significaron las manifestaciones, los levantamientos o la movilización de masas. Luego, porque a lo largo de la historia se pusieron escasos límites a la violencia del ejército y de la policía. A lo que se debe agregar la historia de golpes de estado protagonizados por las fuerzas armadas para imponer sus ideas y sus planes de gobierno. Pero el uso de la violencia por parte de los sectores populares se realiza en medio de manifestaciones de diferentes tipo, no necesariamente violentas. Generalmente esos actos de violencia se produjeron cuando la policía intentaba desalojar una fábrica (en el pasado más lejano) o abrir una ruta al tránsito normal de las personas (en el presente). Aquí habría que señalar que muchas veces la amenaza (o la violencia real) resulta bastante útil a quienes no sólo no tienen ningún poder para hacer oír sus reclamos sino que las probabilidades para alcanzar sus objetivos son más o menos remotas. Cuando los desocupados cortan las rutas reclamando "planes trabajar" o subsidios gubernamentales, más allá del debate que ello pueda generar alrededor de los rasgos de este tipo de demanda y del papel de las organizaciones que canalizan esos planes, las acciones (más o menos violentas) 
se convierten en el único camino para garantizar el logro de sus objetivos concretos y limitados. ${ }^{62}$

Pero en el momento de escribir este artículo las protestas se reproducen cotidianamente a lo largo y lo ancho del país y todavía no se han producido las investigaciones que vayan más allá del debate sobre la crítica situación actual. Los límites de los estudios sobre la protesta social no son sólo para el pasado inmediato. Aunque parece que se ha escrito mucho falta todavía una lectura detenida de las revoluciones, rebeliones y movilizaciones de masas y, sobre todo, del modo en que la gente común se ha involucrado en ellas.

62 Clarín, 8 de mayo de 2001 y 1 al 4 de septiembre de 2002. 